\section{Ventral abdominal herniation through PEG site in a child with cystic fibrosis}

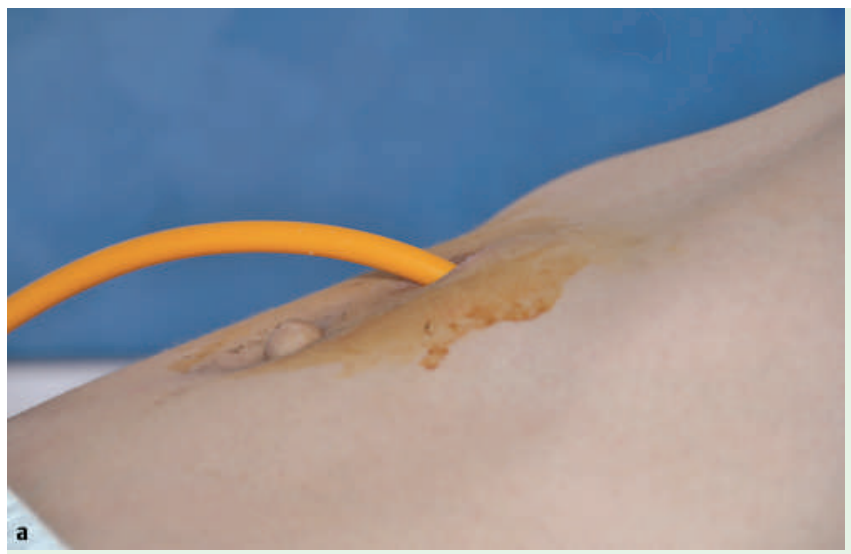

Fig. 1 a Existing PEG site. $\mathbf{b}$ Abdominal bulging became prominent after an excessive cough.

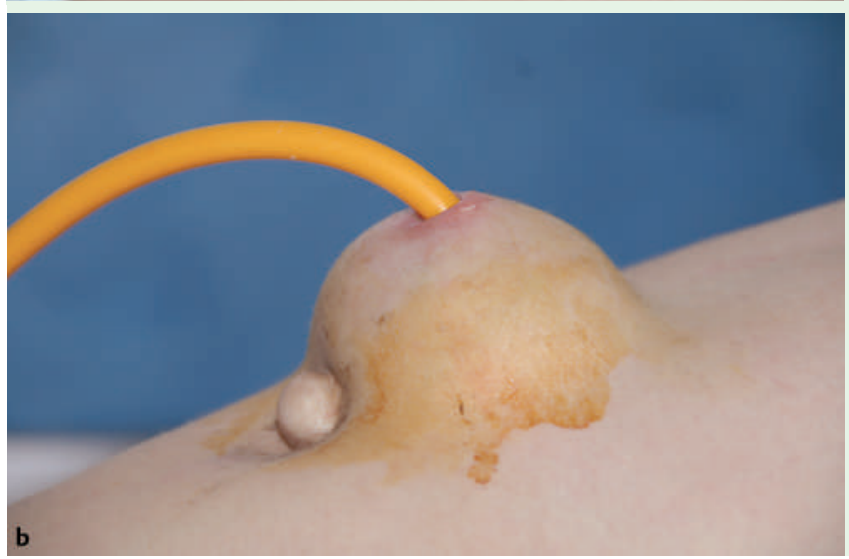

An 8-year-old boy with cystic fibrosis was admitted to hospital because of recurrent respiratory infection. He was below the 5 th percentile for weight, and the Pediatric Gastroenterology Department was consulted for nutritional support. A percutaneous endoscopic gastrostomy (PEG) tube was inserted by standard pull technique (Microvasive, 16F; Boston Scientific Corporation, Natick, Massachusetts, USA). After 4 months, the original gastrostomy tube was removed by traction and replaced by a button device. Two months later, the patient's parents noticed an abdominal bulging at the PEG site. Physical examination revealed a reducible bulge at the PEG site that became more prominent during cough, which was consistent with ventral hernia ( $\bullet$ Fig. 1a,b).

There have been three previously reported cases of abdominal herniation through a PEG site in adults [1-3]. Chuang et al. reported a case of gastric wall herniation alba, or a previous incision - as in our case, a PEG site [4]. The most likely dynamic factor causing the herniation in our patient was increased intra-abdominal pressure due to chronic cough. In addition, placement of the PEG tube at the linea alba probably created a weakness in the abdominal wall. Traction on the PEG tube to replace it with a more ergonomic button device might have also separated the elements of the abdominal wall.

This is the first reported case of a child presenting with abdominal herniation commonly at the umbilical area, the linea through a PEG site. Recommendations to prevent hernia formation at PEG sites include avoiding the linea alba, delaying removal of the PEG tube, avoiding excessive tension on the PEG tube, and having the patient avoid engaging in excessive exercise.

\section{Endoscopy_UCTN_Code_CPL_1AH_2AI}

\section{O. Ozutemiz ${ }^{1}$, N. Oruc ${ }^{1}$, F. Tekin ${ }^{1}$,}

\section{F. Ozgenc ${ }^{2}$, R. Yagci $^{2}$}

${ }^{1}$ Gastroenterology Department, Ege University Faculty of Medicine, Izmir, Turkey

2 Pediatric Gastroenterology Department, Ege University Faculty of Medicine, Izmir, Turkey

\section{References}

1 Chuang $\mathrm{CH}$, Chen $\mathrm{CY}$. Gastric herniation through PEG site. Gastrointest Endosc 2003; 58: 416

2 Boldo-Roda E, Peris-Trias A, Perez de LuciaPenalver $G$ et al. Reflections in front of a case of ventral hernia after PEG tube removal. Gastrointest Endosc 2005; 62: 323 - 324

3 Kaplan R, Delegge $M$. An unusual case of a ventral Richter's hernia at the site of a previous PEG tube. Dig Dis Sci 2006; 51: 2389 2392

4 Park AE, Roth JS, Kavic SM. Abdominal wall hernia. Curr Probl Surg 2006; 43: 326 - 375

Bibliography

DOI $10.1055 / \mathrm{s}-2007-966705$

Endoscopy 2007; 39: E281

(c) Georg Thieme Verlag KG Stuttgart · New York . ISSN 0013-726X

\section{Corresponding author}

\section{N. Oruc, MD}

Gastroenterology Department

Ege University Faculty of Medicine

Bornova

Izmir

35100

Turkey

Fax: +90-232-3427764

nevintr@yahoo.com 